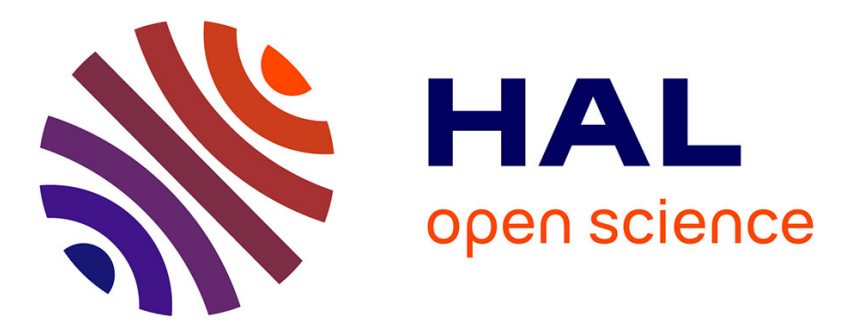

\title{
Heteroaggregation of Titanium Dioxide Nanoparticles with Model Natural Colloids under Environmentally Relevant Conditions
}

Antonia Praetorius, Jérôme Labille, Martin Scheringer, Antoine Thill, Konrad Hungerbühler, Jean-Yves Bottero

\section{To cite this version:}

Antonia Praetorius, Jérôme Labille, Martin Scheringer, Antoine Thill, Konrad Hungerbühler, et al.. Heteroaggregation of Titanium Dioxide Nanoparticles with Model Natural Colloids under Environmentally Relevant Conditions. Environmental Science and Technology, 2014, 48 (18), pp.10690-10698. 10.1021/es501655v . hal-01157196

\author{
HAL Id: hal-01157196 \\ https://hal.science/hal-01157196
}

Submitted on 17 Nov 2015

HAL is a multi-disciplinary open access archive for the deposit and dissemination of scientific research documents, whether they are published or not. The documents may come from teaching and research institutions in France or abroad, or from public or private research centers.
L'archive ouverte pluridisciplinaire HAL, est destinée au dépôt et à la diffusion de documents scientifiques de niveau recherche, publiés ou non, émanant des établissements d'enseignement et de recherche français ou étrangers, des laboratoires publics ou privés. 


\title{
Heteroaggregation of Titanium Dioxide Nanoparticles with Model Natural Colloids under Environmentally Relevant Conditions
}

\author{
Antonia Praetorius, ${ }^{* \dagger}{ }^{\dagger}$ Jérôme Labille, ${ }^{\ddagger}, \mathbb{I}$ Martin Scheringer, ${ }^{\dagger}$ Antoine Thill, $^{\S, I L}$ Konrad Hungerbühler, $^{\dagger}$ \\ and Jean-Yves Bottero \\ ${ }^{\dagger}$ Institute for Chemical and Bioengineering, ETH Zurich, 8093 Zurich, Switzerland \\ ${ }^{\ddagger}$ Aix-Marseille Université, CNRS, IRD, CEREGE UMR 7330, 13545 Aix en Provence, France \\ IInternational Consortium for the Environmental Implications of Nanotechnology, iCEINT, Aix en Provence, France \\ ${ }^{\S}$ Laboratoire Interdisciplinaire sur l'Organisation Nanométrique et Supramoléculaire, UMR CEA-CNRS 3299, CEA Saclay, 91191 \\ Gif-sur-Yvette, France
}

\section{Supporting Information}

ABSTRACT: The heteroaggregation of engineered nanoparticles (ENPs) with natural colloids (NCs), which are ubiquitous in natural surface waters, is a crucial process affecting the environmental transport and fate of ENPs. Attachment efficiencies for heteroaggregation, $\alpha_{\text {hetero, }}$ are required as input parameters in environmental fate models to predict ENP concentrations and contribute to ENP risk assessment. Here, we present a novel method for determining $\alpha_{\text {hetero }}$ values by using a combination of laser diffraction measurements and aggregation modeling based on the Smoluchowski equation. Titanium dioxide nanoparticles $\left(\mathrm{TiO}_{2} \mathrm{NPs}, 15 \mathrm{~nm}\right)$ were used to demonstrate this new approach together with larger silicon dioxide particles $\left(\mathrm{SiO}_{2}, 0.5 \mu \mathrm{m}\right)$

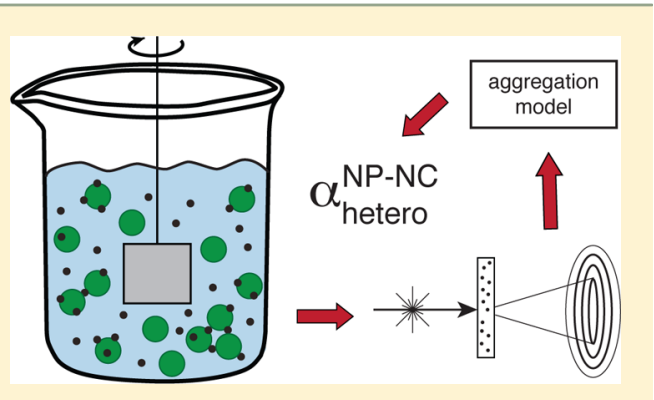
representing NCs. Heteroaggregation experiments were performed at different environmentally relevant solution conditions. At $\mathrm{pH} 5$ the $\mathrm{TiO}_{2} \mathrm{NPs}$ and the $\mathrm{SiO}_{2}$ particles are of opposite charge, resulting in $\alpha_{\text {hetero }}$ values close to 1 . At pH 8, where all particles are negatively charged, $\alpha_{\text {hetero }}$ was strongly affected by the solution conditions, with $\alpha_{\text {hetero }}$ ranging from $<0.001$ at low ionic strength to 1 at conditions with high $\mathrm{NaCl}$ or $\mathrm{CaCl}_{2}$ concentrations. The presence of humic acid stabilized the system against heteroaggregation.

\section{INTRODUCTION}

The challenges associated with assessing the risks of the increased production and use of engineered nanoparticles (ENPs) in a wide range of applications and consumer products have been widely discussed. ${ }^{1,2}$ The new properties of ENPs compared to "conventional" pollutants such as organic chemicals and metals require a review of methods for studying and predicting the behavior of ENPs in different environmental systems. Numerous studies have shown that ENPs readily undergo transformations in the environment and have a high tendency to attach to each other and to other surfaces present in the environment. The form in which ENPs are present in a given environmental matrix (pristine, transformed, free, aggregated, or attached) affects their toxicity, which makes it important to understand transformation pathways of ENPs in complex environmental systems. $^{3-7}$

Until now, much emphasis has been placed on analyzing the homoaggregation (i.e., the aggregation of ENPs among themselves) of ENPs under a wide range of different conditions. $^{8-11}$ However, in realistic environmental situations, the expected concentrations of ENPs, for example, in surface waters, are so low ${ }^{12-15}$ that ENPs will be outnumbered by natural colloids (NCs) (e.g., clays) and heteroaggregation of ENPs with these NCs will be a far more important process than homoaggregation. We demonstrated the importance of heteroaggregation in comparison to other processes affecting the fate of ENPs in a recent modeling case study of $\mathrm{TiO}_{2}$ nanoparticles (NPs) in a river. ${ }^{12}$

While methods of measuring the homoaggregation of ENPs are well established, considerable challenges remain for measurements of heteroaggregation. A binary system of one ENP type and another particle species is more complex than a single-particle system; heteroaggregation needs to be differentiated from simultaneous homoaggregation and different orders of magnitude in size and concentration between the NPs and the NCs require a thoughtful choice of analytical tools. For the results of heteroaggregation experiments to be used for predictions of ENP fate, it is important to consider the required format of the experimental output to be suitable as input for environmental fate models. In this context, (hetero)aggregation rates are not suitable, because they are concentrationdependent. Instead, attachment efficiencies for heteroaggregation, $\alpha_{\text {hetero }}$, which represent the probability of two particles of

\section{Received: April 4, 2014}

Revised: August 13, 2014

Accepted: August 15, 2014

Published: August 15, 2014 
different type to attach and form an aggregate upon collision, need to be identified; they are suitable concentrationindependent input values for fate models. Attachment efficiencies for aggregation (homo- and hetero-) depend strongly on the surface interactions of the aggregating particles and are therefore influenced by the characteristics of the respective particles, as well as the properties of the surrounding medium (i.e., $\mathrm{pH}$, ionic strength and composition and presence of natural organic matter (NOM)). It is therefore necessary to determine $\alpha_{\text {hetero }}$ values specifically for each NP-NC combination of interest and under a wide range of solution conditions.

Recently, a few different approaches have been presented that attempt to determine the heteroaggregation kinetics of ENPs. ${ }^{16-19}$ Huynh et al. ${ }^{17}$ studied the heteroaggregation of oppositely charged multiwalled carbon nanotubes (CNTs) and hematite nanoparticles (HemNPs) using time-resolved dynamic light scattering (DLS) and cryogenic transmission electron microscopy (cryo-TEM) to determine aggregation rates and elucidate aggregation mechanisms. In their study, heteroaggregation rates were determined as a function of the relative $\mathrm{CNT}$ and HemNP concentrations, but attachment efficiencies could only be derived for the homoaggregation experiments, not for heteroaggregation. Furthermore, they worked at one $\mathrm{pH}$ value ( $\mathrm{pH}$ 5.2) and at low ionic strength $(0.1$ $\mathrm{mM} \mathrm{NaCl}$ ), conditions that are not representative of most environmental systems.

The study by Afrooz et al. ${ }^{18}$ was conducted under environmentally more relevant conditions (at $\mathrm{pH} 6.2$ and in a wider range of electrolyte concentrations) with gold nanospheres and plutonic acid (PA) modified single-walled carbon nanotubes (PA-SWNTs), where both NP types are negatively charged, but the PA-SWNTs do not homoaggregate due to the PA coating. Nevertheless, it was also not possible in this study to determine $\alpha_{\text {hetero }}$ values. While $\alpha_{\text {homo }}$ was determined by the classic approach of normalizing the given homoaggregation rate (obtained by time-resolved DLS) with the maximum homoaggregation rate (above the critical coagulation concentration (CCC) of the given electrolyte), this approach could not be employed for the determination of $\alpha_{\text {hetero }}$ because a maximum heteroaggregation rate could not be determined even at high electrolyte concentrations in the experiments performed.

Zhou et al. ${ }^{16}$ are the first to present attachment efficiencies for heteroaggregation $\left(\alpha_{\text {hetero }}\right)$, for the interaction of $\mathrm{TiO}_{2}$ and Ag NPs with montmorillonite (a natural clay mineral). This study also employed time-resolved DLS to measure aggregation rates at $\mathrm{pH} 4$ and $\mathrm{pH} 8$ in a wide range of $\mathrm{NaNO}_{3}$ concentrations. Their method to determine $\alpha_{\text {hetero }}$ values is based on the same approach used for homoaggregation, by normalizing the measured aggregation rate with the fastest aggregation rate. However, the " $\alpha$ hetero" obtained in this way is dependent on the relative NP and clay particle concentrations in the system ${ }^{20}$ and is therefore not suitable as a concentrationindependent input value for ENP fate models.

Finally, Loosli and Stoll ${ }^{19}$ examined the interaction of $\mathrm{TiO}_{2}$ $\mathrm{NPs}$ with micron-sized latex particles in three different $\mathrm{pH}$ regimes $(3.7,6.2$, and 10$)$ at low ionic strength, measuring the aggregation kinetics by following the decrease of free latex particles with a particle sizer (Coulter Counter Multisizer). In this study the electrostatic interactions between the nano- and micron-sized particles at different solution conditions and aggregation mechanisms in these binary systems were studied and discussed in detail, but no attachment efficiencies were reported.

While contributing to an increased understanding of interactions of ENPs in binary systems, none of these studies provides a generalizable method for determining concentrationindependent attachment efficiencies for heteroaggregation, $\alpha_{\text {hetero }}$ in a range of environmentally relevant conditions and applicable to different combinations of ENPs and (natural) colloid particles, which are typically several orders of magnitude larger in size. Here we present a new method for determining the attachment efficiency for heteroaggregation, $\alpha_{\text {hetero, }}$ between ENPs and natural colloids (NCs) using a combination of laser diffraction and a Smoluchowski-based aggregation model. A first application of the method is demonstrated for the heteroaggregation of $\mathrm{TiO}_{2} \mathrm{NPs}$ with $\mathrm{SiO}_{2}$ particles (representing model NCs) at $\mathrm{pH} 5$ and $\mathrm{pH} 8$, where the particles are of opposite and equal surface charge, respectively. The experiments were conducted in a wide range of electrolyte conditions and the effect of humic acid on $\alpha_{\text {hetero }}$ was investigated.

\section{GENERAL CONCEPT}

Our method is designed to work for NPs in the nanometer size range and NCs in the micrometer size range and can be used in a large range of (environmentally relevant) hydrochemical conditions. The general approach is outlined in Figure 1. We differentiate between two generations of heteroaggregates: "primary heteroaggregates" consist of one NC with one or more attached NPs, their size remaining similar to that of the bare and dispersed NCs. "Secondary heteroaggregates" result from the further aggregation of primary heteroaggregates and involve at least two NCs. The secondary heteroaggregates thus display a size significantly larger than dispersed primary heteroaggregates or bare NCs (Figure 1a).

Under most environmentally relevant situations, the NPs and NCs will differ by at least one order of magnitude both in size and concentration, which makes a direct, time-resolved measurement of the attachment of the NP and NC and formation of primary heteroaggregates nearly impossible. Instead, we measure the aggregation rate of the primary heteroaggregates to form secondary heteroaggregates and then use a numerical method to determine the original attachment efficiency between the NPs and NCs, $\alpha_{\text {hetero }}$.

The aggregation kinetics are measured by time-resolved laser diffraction (Figure $1 \mathrm{~b}$ ). The scattered intensity of the laser diffractometer decreases strongly (by the power of 6) with decreasing size, therefore the signal is blind to the NPs (also present at much lower concentration than the NCs) and only the aggregation of NCs or primary heteroaggregates is measured. The experiments are carried out in a system of well controlled hydrological conditions (see Materials and Method section), which is connected by a pump to the measuring cell of the laser diffractometer, and the aggregation of the suspension of NPs and NCs is measured as a function of time (Figure $1 \mathrm{~b}$ ). The NC concentration is kept constant and different NP concentrations are tested until heteroaggregation of NPs and NCs leads to the formation of measurable secondary heteroaggregates.

The experimental output is then analyzed by a Smoluchowski-based aggregation model (referred to as the Smolu-Model). This model can simulate homoaggregation kinetics and is parametrized with the specific experimental conditions of a given aggregation experiment. Model output is presented as the variation of the volume-weighted median particle size $\left(D_{\mathrm{v}, 50}\right)$ as 
a) Formation of larger heteroaggregates from nano-colloid heteroaggregates (NCHA) following NP-NC heteroaggregation

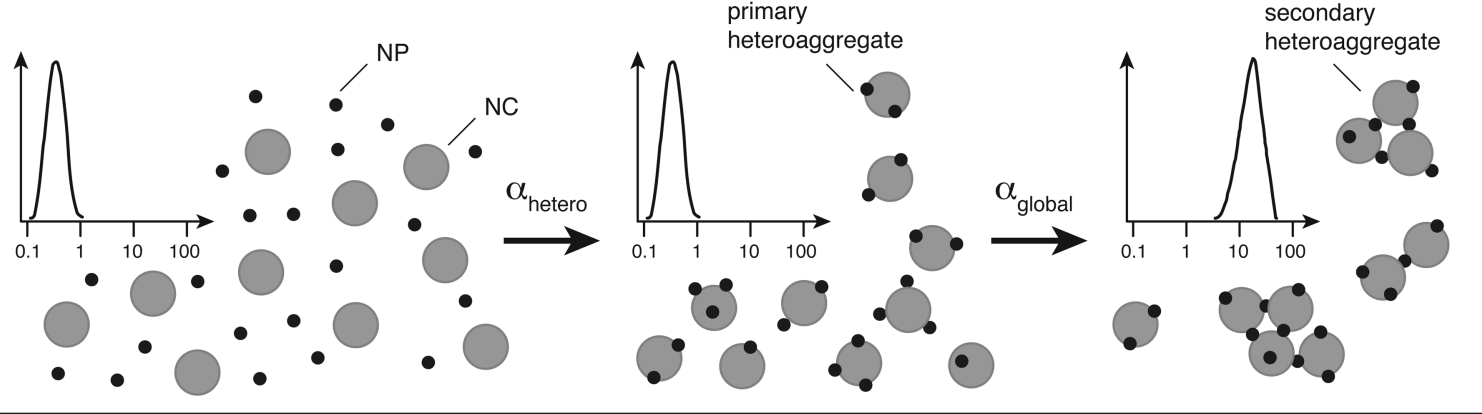

b) Experimental set-up of time-resolved laser diffraction size measurements

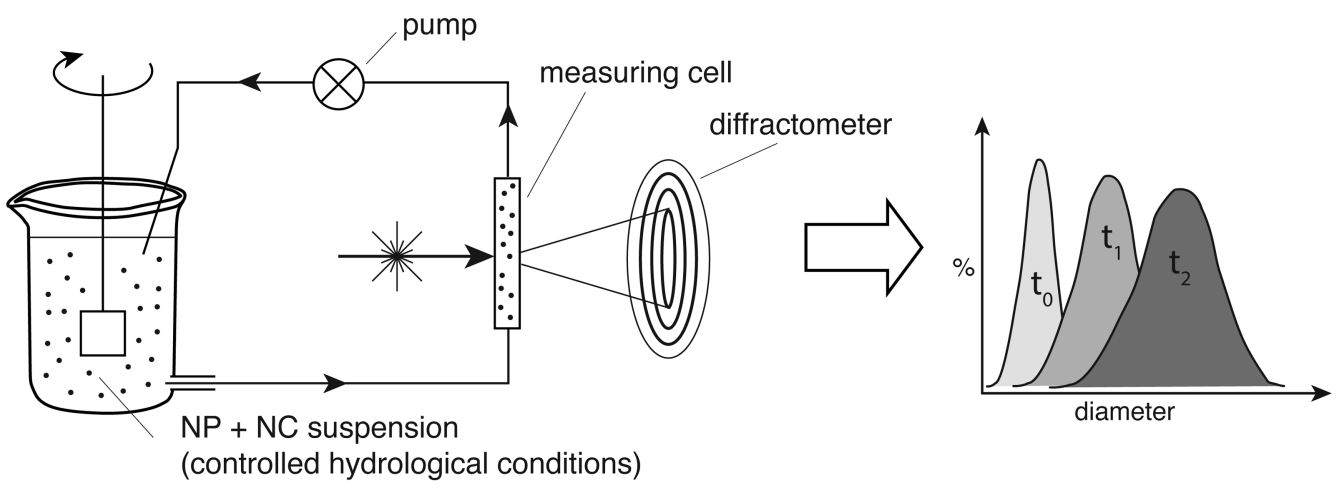

c) Determination of attachment efficiency from experimental data \& aggregation model

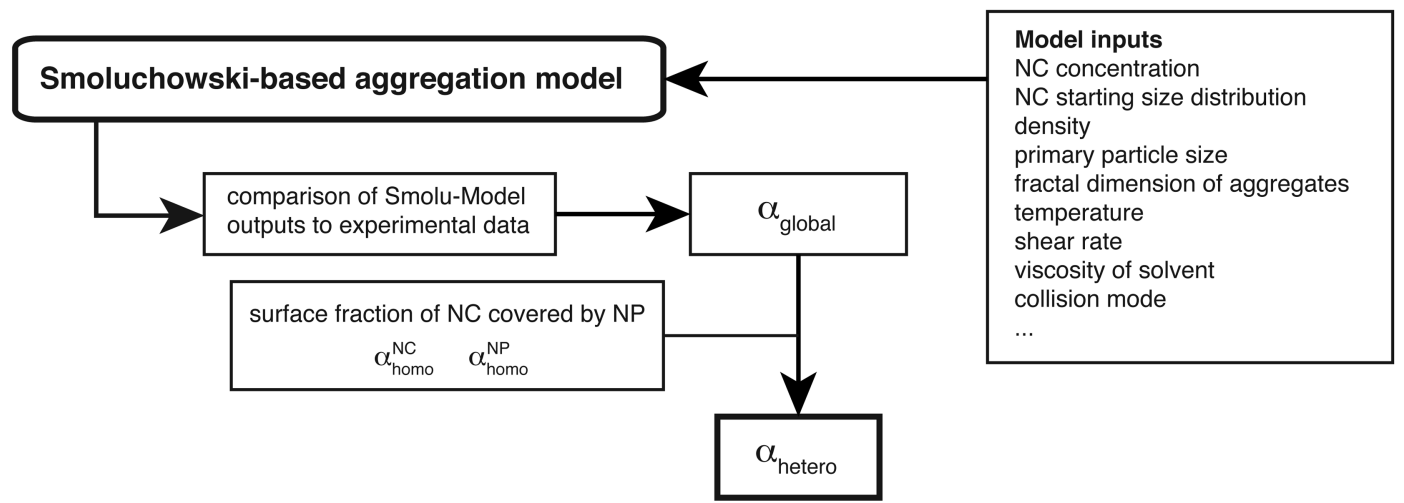

Figure 1. Overview of the general concept developed in this study to determine attachment efficiencies for heteroaggregation, $\alpha_{\text {hetero }}$ (a) The aggregation of small NPs with larger NCs, first forming NP-NC primary heteroaggregates which then further aggregate with each other to form larger secondary heteroaggregates. (b) Experimental setup. (c) The data interpretation with an aggregation model and calculation of $\alpha_{\text {hetero }}$ is visualized.

a function of time, which can be directly compared to the experimental output from the laser diffractometer. From this comparison one can then obtain the attachment efficiency $\left(\alpha_{\text {global }}\right)$ that best corresponds to the observed aggregation of the primary to secondary heteroaggregates (Figure 1c) and in a next step calculate the attachment efficiency of heteroaggregation between the NPs and the NCs $\left(\alpha_{\text {hetero }}\right)$.

In this study we use $\mathrm{TiO}_{2} \mathrm{NPs}(5-30 \mathrm{~nm})$ and $0.5 \mu \mathrm{m} \mathrm{SiO}$ particles to represent model NCs. Commercial $\mathrm{SiO}_{2}$ particles with a narrow size distribution were chosen for this initial study to enable a specific model parametrization and assess the validity of this new method. At the same time, $\mathrm{SiO}_{2}$ particles are a good first approximation of natural NCs, which are typically composed, among others, of a large fraction of $\mathrm{SiO}_{2}$ minerals. The heteroaggregation experiments are conducted at $\mathrm{pH} \mathrm{5}$, where the NPs and NCs have an opposite surface charge and $\alpha_{\text {hetero }}$ is expected to be close to 1 , which enables us to constrain and validate the approach, and at $\mathrm{pH} 8$, which is more representative of realistic environmental conditions and where both the NPs and NCs are negatively charged and are likely to undergo more repulsive interactions, that is, lower $\alpha_{\text {hetero }}$.

\section{MATERIALS AND METHODS}

Preparation of $\mathrm{SiO}_{2}$ and $\mathrm{TiO}_{2}$ Suspensions. Monodisperse spherical silicon dioxide $\left(\mathrm{SiO}_{2}\right)$ particles with a narrow size distribution around $0.5 \mu \mathrm{m}$ were purchased from Alfa Aesar (Silicon(IV) oxide, powder, $0.5 \mu \mathrm{m}, 99.9 \%$ ) in powder form. A stock suspension of $0.5 \mathrm{~g} / \mathrm{L} \mathrm{SiO}_{2}$ was prepared by ultrasonication of the $\mathrm{SiO}_{2}$ powder in Milli-Q water for $15 \mathrm{~min}$ and stirring the suspension at room temperature until use. Fresh 
stock suspension was prepared not more than $24 \mathrm{~h}$ before each experiment.

Titanium dioxide nanoparticles $\left(\mathrm{TiO}_{2} \mathrm{NPs}\right)(65 \%$ anatase, $35 \%$ brookite) with a primary particle size of 5-30 nm were obtained from Nanostructured and Amorphous Material Inc. (titanium oxide (anatase 5-30 nm) in water). The $\mathrm{TiO}_{2} \mathrm{NPs}$ were pure, not coated and were purchased dispersed in an aqueous suspension at acidic $\mathrm{pH}$, with a concentration of 170 $\mathrm{g} / \mathrm{L}$ and a specific surface area of $193 \mathrm{~m}^{2} / \mathrm{g}$.

Solution Chemistry. Suwanee River Humic Acid (SRHA, Standard II) was purchased from the International Humic Substances Society. A stock solution of $0.5 \mathrm{~g} / \mathrm{L}$ was prepared by dissolving SRHA in Milli-Q water (stirring $12 \mathrm{~h}$, r.t., in the dark) and adjusting the $\mathrm{pH}$ to 8.0 by addition of $0.2 \mathrm{M} \mathrm{NaOH}$. The stock solution was stored at $4{ }^{\circ} \mathrm{C}$ in the dark until further use.

All suspensions were prepared with ultrapure Milli-Q water $\left(18.2 \mathrm{M} \Omega \mathrm{cm}^{-1}\right)$. Hydrochloric acid $(\mathrm{HCl}, 0.1 \mathrm{M})$ and sodium hydroxide $(\mathrm{NaOH}, 0.2 \mathrm{M})$ were used to adjust the $\mathrm{pH}$ of the experiment suspensions. All experiments at $\mathrm{pH} 8$ were prepared with a background concentration of $1 \mathrm{mM}$ sodium bicarbonate $\left(\mathrm{NaHCO}_{3}\right)$ to facilitate $\mathrm{pH}$ adjustment. Sodium chloride $(\mathrm{NaCl})$ and calcium chloride $\left(\mathrm{CaCl}_{2}\right)$ were used to adjust the solution ionic strength.

Electrophoretic Mobility Measurements. A Malvern Zetasizer NanoZS was used to determine the electrophoretic mobility (EPM) of the $\mathrm{SiO}_{2}$ and $\mathrm{TiO}_{2}$ at different solution conditions. The EPM of $\mathrm{SiO}_{2}$ was measured at a concentration of $100 \mathrm{mg} / \mathrm{L}$ and for the $\mathrm{TiO}_{2} \mathrm{NPs}$ at a concentration of $1 \mathrm{mg} /$ L. In both cases, the $\mathrm{NaCl} / \mathrm{CaCl}_{2}$, SRHA concentration and $\mathrm{pH}$ were adjusted as required for each experiment.

Size Distribution Measurements and Homoaggregation Kinetics of $\mathrm{TiO}_{2}$ NPs. The initial size distribution and homoaggregation kinetics of the $\mathrm{TiO}_{2} \mathrm{NPs}$ were measured by time-resolved DLS on the Malvern Zetasizer NanoZS under different solution conditions. The measurements were performed at a $\mathrm{TiO}_{2}$ concentration of $10 \mathrm{mg} / \mathrm{L}$, which is 1 order of magnitude higher than used in the heteroaggregation experiments but was required to reach a sufficiently strong signal on the DLS.

$\mathrm{SiO}_{2}$ Homo- and Heteroaggregation Kinetics Determination. The initial size distribution of the $\mathrm{SiO}_{2}$ suspensions, as well as the homoaggregation kinetics of the $\mathrm{SiO}_{2}$ particles and the heteroaggregation kinetics of the $\mathrm{SiO}_{2}$ particles in the presence of $\mathrm{TiO}_{2} \mathrm{NPs}$ were measured by laser diffractometry, using the Malvern Mastersizers S and 3000. The experimental setup is illustrated in Figure 1b. The experiments were carried out in a system of well-controlled hydrological conditions in a 1-L beaker connected to the measurement cell of the laser diffractometer. The beaker contained four equally spaced baffles and a calibrated agitator to achieve an average velocity gradient $G$ of $100 \mathrm{~s}^{-1}$ in the beaker. ${ }^{21}$ While the shear in the tubes connecting the beaker to the measurement cell could not be precisely adjusted, the experimental suspension was continuously pumped through the system at a constant speed of 100 $\mathrm{mL} / \mathrm{min}$ and the tubes were kept as short as possible to ensure reproducible conditions between different experiments and minimize the effect of the shear in the tube on the overall aggregation kinetics of the system.

For each aggregation experiment, the $\mathrm{SiO}_{2}$ and $\mathrm{TiO}_{2}$ suspensions were freshly prepared. If not otherwise noted, the heteroaggregation experiments were performed at an $\mathrm{SiO}_{2}$ concentration of $100 \mathrm{mg} / \mathrm{L}$ and $\mathrm{a} \mathrm{TiO}_{2}$ concentration of 0.8 $\mathrm{mg} / \mathrm{L}$. The $\mathrm{SiO}_{2}$ suspensions were prepared by diluting the 0.5 $\mathrm{g} / \mathrm{L} \mathrm{SiO}_{2}$ stock suspension with Milli-Q water to reach $400 \mathrm{~mL}$ of suspension at the desired concentration, applying ultrasonication for $20 \mathrm{~min}$ to ensure full dispersion, adding the electrolyte and, if required, a given volume of the SRHA stock solution and adjusting the $\mathrm{pH}$ (the $\mathrm{pH}$ was then monitored during the experiment to ensure any observed aggregation is not a $\mathrm{pH}$ effect). The $\mathrm{TiO}_{2}$ suspensions were prepared by diluting the $170 \mathrm{~g} / \mathrm{L} \mathrm{TiO}_{2}$ stock suspension with Milli-Q water to reach $400 \mathrm{~mL}$ of suspension at the desired concentration and adjusting the $\mathrm{pH}$. This approach of mixing equal volumes of NP and NC suspensions was chosen to favor rapid and homogeneous mixing of the system. For the $\mathrm{SiO}_{2}$ homoaggregation experiments the $400 \mathrm{~mL}$ of $\mathrm{TiO}_{2}$ suspension were replaced by $400 \mathrm{~mL} \mathrm{NaCl}$ or $\mathrm{CaCl}_{2}$ solutions. The $\mathrm{SiO}_{2}$ suspension was mixed with the $\mathrm{TiO}_{2}$ suspension or electrolyte solution in the experiment beaker at time $t_{0}$ and the change in size distribution was measured over time.

Determination of Attachment Efficiencies with the Smolu-Model. The aggregation data were analyzed with a numerical aggregation model based on the Smoluchowski equation. $^{22}$ The Smolu-Model, which was developed previously $^{22}$ and is briefly described in the Section S1 of the Supporting Information, was parametrized to match the experimental conditions (particle characteristics, hydrological conditions, temperature etc.) and was used to determine the attachment efficiency, $\alpha_{\text {global }}$, which describes the aggregation process of primary to secondary heteroaggregates (Figure 1a), for each experiment. A list of the most important model parameters is given in Table S1 in the Supporting Information, along with an overview of the specific parameters for the different aggregation experiments in Supporting Information Table S2. Note that the Smolu-Model predicts aggregation of one type of particles (homoaggregation) and was parametrized for the $\mathrm{SiO}_{2}$ particles to fit the $\mathrm{SiO}_{2}$ homoaggregation experiments and for the $\mathrm{TiO}_{2}-\mathrm{SiO}_{2}$ primary heteroaggregates for the heteroaggregation experiments. Knowing the surface fraction of NCs covered by NPs, $f_{\mathrm{NP}}$, and the attachment efficiencies for homoaggregation for both the NPs $\left(\alpha_{\text {homo }}^{\mathrm{NP}}\right)$ and the NCs $\left(\alpha_{\text {homo }}^{\mathrm{NC}}\right)$ under the given hydrochemical conditions it is possible to estimate the attachment efficiency of heteroaggregation between NPs and NCs $\left(\alpha_{\text {hetero }}\right)$ according to eq 1 .

$$
\alpha_{\text {hetero }}=\frac{\alpha_{\text {global }}-f_{\mathrm{NP}}{ }^{2} \cdot \alpha_{\text {homo }}^{\mathrm{NP}}-\left(1-f_{\mathrm{NP}}\right)^{2} \cdot \alpha_{\text {homo }}^{\mathrm{NC}}}{2 \cdot\left(1-f_{\mathrm{NP}}\right) \cdot f_{\mathrm{NP}}}
$$

A derivation of eq 1 is given in section S2 of the Supporting Information. The use of eq 1 in combination with the SmoluModel is based on the assumption that the NPs rapidly attach to the NCs' surface (due to high collision frequencies as a result of high particle concentrations) and distribute uniformly on the NC surface. Furthermore, we assume that the attachment efficiencies $\left(\alpha_{\mathrm{hP}}^{\mathrm{NP}}, \alpha_{\mathrm{homo}}^{\mathrm{NC}}\right.$, and $\left.\alpha_{\text {hetero }}\right)$ remain unaffected by the aggregation state of the particles and therefore the attachment efficiencies derived from the aggregation behavior of the secondary heteroaggregates are assumed to correspond well to the attachment efficiencies of the free particles. This is based on the assumption that the surface properties (e.g., surface charge) do not change significantly upon aggregation. ${ }^{23}$

Determination of Aggregate Fractal Dimension. The fractal dimension, $D_{\mathfrak{f}}$, of the aggregates is an important input parameter to the aggregation model as it describes the aggregate structure and strongly affects the collision mode 

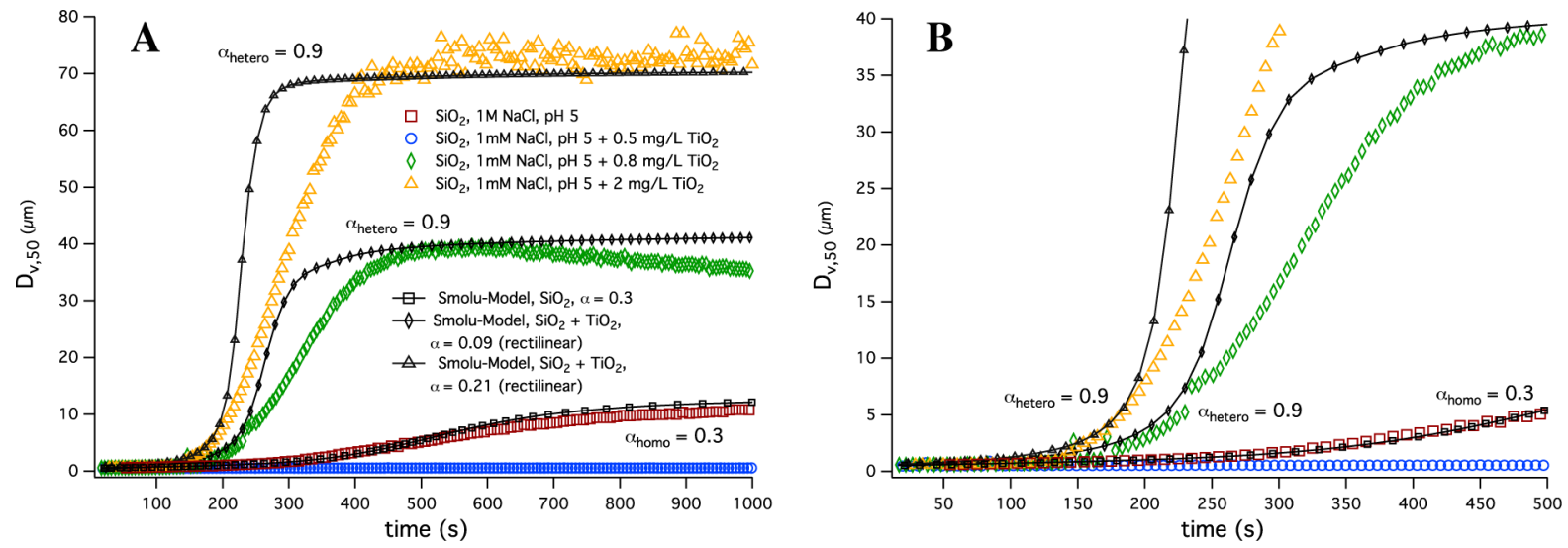

Figure 2. (A) Example of analysis of aggregation data with the Smolu-Model for homoaggregation of $100 \mathrm{mg} / \mathrm{L} \mathrm{SiO}{ }_{2}$ and heteroaggregation of 100 $\mathrm{mg} / \mathrm{L} \mathrm{SiO}{ }_{2}$ and $\mathrm{TiO}_{2}$ at $\mathrm{pH}$ 5. (B) Zoom into the initial aggregation stages.

and aggregate growth rate. For each experiment, $D_{\mathrm{f}}$ was determined from the laser diffraction data by plotting the raw data in terms of the scattered intensity as a function of the wave vector, as described elsewhere. ${ }^{24}$

\section{RESULTS AND DISCUSSION}

Material Properties at Different Solution Conditions. The $\mathrm{SiO}_{2}$ particles form a stable suspension with a narrow size distribution around $0.5 \mu \mathrm{m}$ at $\mathrm{pH} 5$ and 8 (Figure S4A, Supporting Information). The $\mathrm{SiO}_{2}$ particles are of neutral charge at $\mathrm{pH} \quad 1.3$ and display an increasingly negative electrophoretic mobility (EPM) at higher $\mathrm{pH}$ values (Supporting Information Figure S2).

The $\mathrm{TiO}_{2} \mathrm{NPs}$ form a suspension around $15 \mathrm{~nm}$ average diameter (Figure S4A, Supporting Information). They are positively charged at $\mathrm{pH} 5$ and negatively charged at $\mathrm{pH} 8$, with an isoelectric point around $\mathrm{pH} 6.5$ (Supporting Information Figure S2). These characteristics are in good agreement with the data measured by Loosli and Stoll ${ }^{19}$ for the same material.

The effect of increasing electrolyte concentration on the surface charge of the $\mathrm{SiO}_{2}$ particles and the $\mathrm{TiO}_{2} \mathrm{NPs}$ was studied at $\mathrm{pH} 8$ by varying the $\mathrm{NaCl}$ concentration between 1 and $500 \mathrm{mM}$ (Supporting Information Figure S3) and the $\mathrm{CaCl}_{2}$ concentration between 0.1 and $50 \mathrm{mM}$ (Supporting Information Figure S3). The EPM of the $\mathrm{SiO}_{2}$ remains negative throughout most of the electrolyte range studied, decreasing from -5.8 to $-1.3 \times 10^{-8} \mathrm{~m}^{2} \mathrm{~V}^{-1} \mathrm{~s}^{-1}$ between 1 and $500 \mathrm{mM}$ $\mathrm{NaCl}$ (and from -4.2 to $+0.5 \times 10^{-8} \mathrm{~m}^{2} \mathrm{~V}^{-1} \mathrm{~s}^{-1}$ for $\mathrm{CaCl}_{2}$ between 0.1 and $50 \mathrm{mM}$ ). The $\mathrm{TiO}_{2} \mathrm{NPs}$ display a less negative surface potential than the $\mathrm{SiO}_{2}$ particles in all cases and reach close to neutral charge at $500 \mathrm{mM} \mathrm{NaCl}$ and $10 \mathrm{mM} \mathrm{CaCl}_{2}$. The decrease of EPM with increasing electrolyte concentration for both $\mathrm{SiO}_{2}$ and $\mathrm{TiO}_{2}$ is in accordance with the expected electrical double layer compression because of the presence of electrolytes.

Homoaggregation Kinetics at $\mathrm{pH} 5$ and 8. Before determining the heteroaggregation kinetics of the $\mathrm{SiO}_{2}-\mathrm{TiO}_{2}$ system it was required to determine the homoaggregation

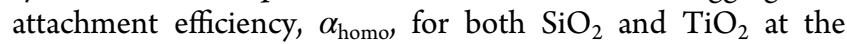
different solution conditions to later calculate $\alpha_{\text {hetero }}$ from the laser diffraction data with eq 1 . The results of the homoaggregation experiments are presented in more detail in section S4 in the Supporting Information.

Heteroaggregation Kinetics at pH 5 (Attractive Charges). The first set of heteroaggregation experiments was performed at $\mathrm{pH} 5(1 \mathrm{mM} \mathrm{NaCl})$. At $\mathrm{pH} 5$, the $\mathrm{SiO}_{2}$ particles are negatively charged (EPM of $-4.2 \times 10^{-8} \mathrm{~m}^{2} \mathrm{~V}^{-1} \mathrm{~s}^{-1}$ ) and the $\mathrm{TiO}_{2} \mathrm{NPs}$ are positively charged $\left(\mathrm{EPM}\right.$ of $+2.5 \times 10^{-8} \mathrm{~m}^{2}$ $\left.\mathrm{V}^{-1} \mathrm{~s}^{-1}\right)$. Accordingly, a strong attraction between the $\mathrm{SiO}_{2}$ particles and the $\mathrm{TiO}_{2}$ was expected. Under these conditions both the $\mathrm{SiO}_{2}$ and $\mathrm{TiO}_{2}$ particles do not homoaggregate $\left(\alpha_{\text {homo }} \mathrm{SiO}_{2} / \mathrm{TiO}_{2}<0.001\right)$, therefore any observed aggregation is expected to be only a result of heteroaggregation between $\mathrm{SiO}_{2}$ and $\mathrm{TiO}_{2}$.

The heteroaggregation experiments were performed in the experimental setup illustrated in Figure $1 \mathrm{~b}$ at an $\mathrm{SiO}_{2}$ concentration of $100 \mathrm{mg} / \mathrm{L}$ and a set of different $\mathrm{TiO}_{2} \mathrm{NP}$ concentrations $(0.1,0.5,0.8,1.0,2.0 \mathrm{mg} / \mathrm{L})$. Up to a concentration of $0.5 \mathrm{mg} / \mathrm{L} \mathrm{TiO}_{2}$ (which corresponds to a surface coverage, $f_{\mathrm{NP}}$, of the $\mathrm{SiO}_{2}$ by the $\mathrm{TiO}_{2} \mathrm{NPs}$ of $3 \%$ ) no heteroaggregation of the $\mathrm{SiO}_{2}-\mathrm{TiO}_{2}$ system is observed (Figure 2), despite the expected $\alpha_{\text {hetero }}$ of 1 . However, upon addition of $0.8 \mathrm{mg} / \mathrm{L} \mathrm{TiO}_{2}$ fast heteroaggregation of the $\mathrm{SiO}_{2}-$ $\mathrm{TiO}_{2}$ system is induced (Figure 2). This $\mathrm{TiO}_{2}$ concentration represents an $f_{\mathrm{NP}}$ of approximately $5 \%$, which appears to be the critical dose of $\mathrm{TiO}_{2} \mathrm{NPs}$ covering the $\mathrm{SiO}_{2}$ surface required to induce secondary aggregation of the $\mathrm{SiO}_{2}-\mathrm{TiO}_{2}$ primary heteroaggregates. It seems that the threshold $f_{\mathrm{NP}}$ for secondary heteroaggregation might be related to the overall surface charge of the heteroaggregates. While at $0.5 \mathrm{mg} / \mathrm{L} \mathrm{TiO}_{2}$ and $100 \mathrm{mg} / \mathrm{L}$ $\mathrm{SiO}_{2}$ the effective EPM of the system is around $-2.0 \pm 0.5 \times$ $10^{-8} \mathrm{~m}^{2} \mathrm{~V}^{-1} \mathrm{~s}^{-1}$, resulting in strong repulsion of the primary heteroaggregates, at $1 \mathrm{mg} / \mathrm{L} \mathrm{TiO}_{2}$ the overall charge of the particles is almost neutral (EPM of $-0.1 \pm 0.1 \times 10^{-8} \mathrm{~m}^{2} \mathrm{~V}^{-1}$ $\mathrm{s}^{-1}$ ). This observation suggests a heteroaggregation mechanism, where the NPs attached to the surface of the $\mathrm{SiO}_{2}$ particles progressively screen the surface charge of the silica until the primary heteroaggregates can come close enough to each other to undergo attractive electrostatic interactions via NP bridges. We assume that such bridges, where one NP connects two neighboring silica surfaces, represent the main type of bond enabling the secondary heteroaggregation process.

Interestingly, the overall heteroaggregation rate observed in the presence of $\mathrm{TiO}_{2} \mathrm{NPs}$ is higher than the maximum homoaggregation rate of $\mathrm{SiO}_{2}$ achieved with the addition of salt. This suggests that the secondary $\mathrm{TiO}_{2}-\mathrm{SiO}_{2}$ heteroaggregates have a different, more stable, structure than the $\mathrm{SiO}_{2}$ homoaggregates. This is due to the strong attractive electrostatic forces between the $\mathrm{SiO}_{2}$ and $\mathrm{TiO}_{2}$ particles due to their 

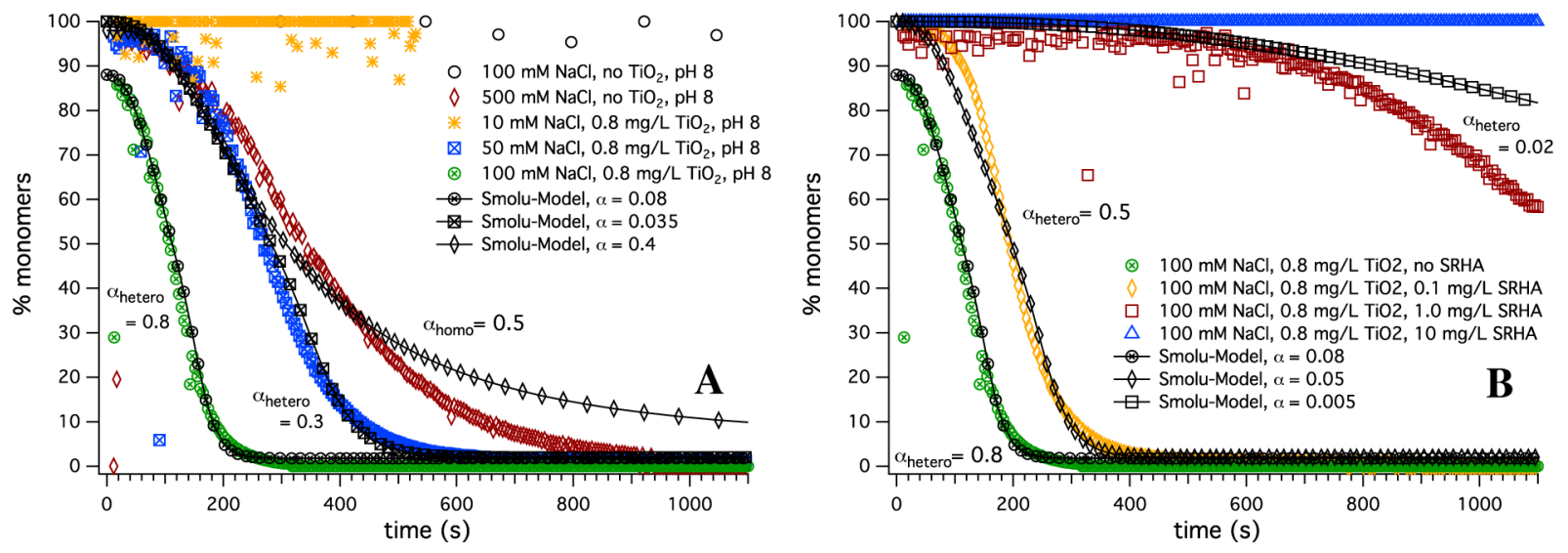

Figure 3. Heteroaggregation of $100 \mathrm{mg} / \mathrm{L} \mathrm{SiO}$ with $\mathrm{TiO}_{2}$ NPs under different solution conditions at $\mathrm{pH}$ 8: (A) $\mathrm{NaCl}$ and (B) $\mathrm{NaCl}+\mathrm{SRHA}$. SRHA = Suwannee River Humic Acid. Note: The monomers for $100 \mathrm{mM} \mathrm{NaCl}, 0.8 \mathrm{mg} / \mathrm{L} \mathrm{TiO}$ (green circles) start below $100 \%$ because of a few large bubbles in the system; the model parametrization was adjusted accordingly to correctly represent the aggregation kinetics.

respective charges under these conditions providing additional stability to the heteroaggregates.

To obtain the attachment efficiencies of the heteroaggrega-

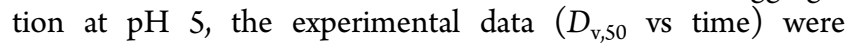
compared to the Smolu-Model output. An example of the assessment for the homo- and heteroaggregation experiments at $\mathrm{pH} 5$ is provided in Figure 2. The model parameters were adjusted to represent the experimental conditions (Supporting Information Table S2), the model was run with different $\alpha$ values (representing the attachment efficiency between the $\mathrm{TiO}_{2}-\mathrm{SiO}_{2}$ primary heteroaggregates $\left.\left(\alpha_{\text {global }}\right)\right)$ until the best visual match was found with the experimental data. Here the focus was on the initial stages of the aggregation, until the aggregates reach approximately $5 \mu \mathrm{m}$ in size (Figure $2 \mathrm{~B}$ ), because at later stages of the aggregation the aggregates become more polydisperse and their fractal dimension is expected to differ compared to the smaller aggregates. This cannot be reflected by the Smolu-Model, which assumes a constant $D_{\mathrm{f}}$ throughout one simulation. Therefore, at later stages of the aggregation, the match between the experimental data and the model is less satisfactory.

The aggregate structure strongly affects the collision frequency because the porosity of an aggregate determines the effect of fluid drag forces on the particle trajectories. ${ }^{22,25}$ The Smolu-Model accounts for this effect by allowing the selection of different collision modes, namely a rectilinear, a curvilinear or an intermediate collision mode, ${ }^{22}$ which can have a strong effect on the predicted aggregation curves. For the homoaggregation experiments an intermediate approximation (between rectilinear and curvilinear collision) was assumed. ${ }^{22,25}$ To account for the additional electrostatic attraction between the colliding particles at $\mathrm{pH} 5$ a rectilinear collision mode was chosen to represent the collision of the heteroaggregates in the Smolu-Model.

The overall attachment efficiency of the binary system, $\alpha_{\text {global }}$ at $0.8 \mathrm{mg} / \mathrm{L} \mathrm{TiO}_{2}$ was estimated with the Smolu-Model to be 0.09 (the faster heteroaggregation rate of the system compared to the homoaggregation rate of $\mathrm{SiO}_{2}$ with $\alpha_{\text {homo }}=0.3$ is explained by the different collision mode despite the lower overall $\alpha$ ). From the attachment efficiencies for the homoaggregation of both particle types at the same conditions $\left(\alpha_{\text {homo }} \mathrm{SiO}_{2}\right.$ and $\left.\alpha_{\text {homo }}\right)$ and the surface fraction of $\mathrm{SiO}_{2}$ covered by $\mathrm{TiO}_{2} \mathrm{NPs}, f_{\mathrm{NP}}$, the heteroaggregation attachment efficiency $\alpha_{\text {hetero }}$ was calculated with eq 1 . For the heteroaggregation experiment at a $\mathrm{TiO}_{2}$ concentration of $0.8 \mathrm{mg} / \mathrm{L}$ (Figure 2) an attachment efficiency for heteroaggregation, $\alpha_{\text {hetero }}$ of 0.9 was obtained. When the same experiment was repeated at a higher $\mathrm{TiO}_{2}$ concentration of $2 \mathrm{mg} / \mathrm{L}$ (corresponding to an $f_{\mathrm{NP}}$ of $13 \%)$ a faster heteroaggregation rate was observed (Figure 2). The $\alpha_{\text {global }}$ obtained from this data with the Smolu-Model is equal to 0.21 . Following eq 1 we also obtain an $\alpha_{\text {hetero }}$ of 0.9 , which shows that the method is independent of the respective NP and NC concentrations. This $\alpha_{\text {hetero }}$ value represents very favorable heteroaggregation conditions as expected from the favorable interaction between the oppositely charged $\mathrm{SiO}_{2}$ and $\mathrm{TiO}_{2}$ particles at $\mathrm{pH} 5$, which validates our initial assumptions.

Heteroaggregation Kinetics at pH 8 (Repulsive Charges). After validating the new method for determining attachment efficiencies for heteroaggregation at $\mathrm{pH} 5$ and low electrolyte conditions, a more extensive set of heteroaggregation experiments was performed at $\mathrm{pH} 8$ and over a wider range of hydrochemical conditions (varying $\mathrm{NaCl}, \mathrm{CaCl}_{2}$, and SRHA concentrations), which are more environmentally relevant. All experiments were performed at an $\mathrm{SiO}_{2}$ concentration of 100 $\mathrm{mg} / \mathrm{L}$ and $\mathrm{a}_{\mathrm{TiO}_{2}}$ concentration of $0.8 \mathrm{mg} / \mathrm{L}$. Selected heteroaggregation experiments at $\mathrm{pH} 8$ are shown in Figure 3 for $\mathrm{NaCl}$ and Figure $\mathrm{S} 8$ in the Supporting Information for $\mathrm{CaCl}_{2}$. The heteroaggregates reached much larger final sizes (up to $100 \mu \mathrm{m}$ ) whereas the homoaggregates generally did not reach sizes larger than $20 \mu \mathrm{m}$. Therefore, to facilitate the visual comparison of the heteroaggregation experiments with the $\mathrm{SiO}_{2}$ homoaggregation experiments, aggregation measurements at $\mathrm{pH} 8$ are displayed in Figure 3 as the volume \% of monomers (NCs or primary heteroaggregates represented by sizes below $1.2 \mu \mathrm{m})$ versus time.

At $\mathrm{pH} 8$ the $\mathrm{SiO}_{2}$ particles and the $\mathrm{TiO}_{2}$ NPs are both negatively charged and as expected at low electrolyte conditions $(10 \mathrm{mM} \mathrm{NaCl})$ no heteroaggregation is observed (Figure $3 \mathrm{~A}$ ) because of electrostatic repulsion. Upon addition of $50 \mathrm{mM}$ $\mathrm{NaCl}$ or $0.1 \mathrm{mM} \mathrm{CaCl} 2$ a slow heteroaggregation is observed; the maximum heteroaggregation rate is achieved with $100 \mathrm{mM}$ $\mathrm{NaCl}$ or $1 \mathrm{mM} \mathrm{CaCl}_{2}$ (Figure 3, Supporting Information Figure S8). Although the $\mathrm{SiO}_{2}$ and $\mathrm{TiO}_{2}$ are not of opposite charge at $\mathrm{pH} \mathrm{8}$, the maximum aggregation rate observed for the heteroaggregation is again higher than the maximum homoaggregation rate at $\mathrm{pH} 8$. Analysis of the fractal dimension of the aggregates revealed that the secondary $\mathrm{SiO}_{2}-\mathrm{TiO}_{2}$ heteroaggregates formed are less dense $\left(D_{\mathrm{f}}\right.$ between 2.0 and 
2.1) than the $\mathrm{SiO}_{2}$ homoaggregates ( $D_{\mathrm{f}}$ between 2.2 and 2.4), which indicates different aggregation mechanisms for both cases. This can be explained by the $\mathrm{TiO}_{2} \mathrm{NPs}$ forming bridges between the $\mathrm{SiO}_{2} \mathrm{NCs}$, leading to the formation of looser aggregate structures which in turn results in a more rectilinear collision mechanism between such heteroaggregates. The $\mathrm{SiO}_{2}$ homoaggregates, on the other hand, form denser structures; therefore their aggregation mode is better represented by a curvilinear or intermediate collision mode.

Next, the heteroaggregation data were analyzed with the Smolu-Model and eq 1 was used to estimate $\alpha_{\text {hetero }}$ (Figure 3, Supporting Information Figure S8, and Table 1). To represent

\section{Table 1. Overview of $\alpha_{\text {hetero }}$ Values at Different Solution} Conditions $^{a}$

$\begin{array}{cccccl}\mathrm{pH} & \begin{array}{c}{[\mathrm{NaCl}]} \\ (\mathrm{mM})\end{array} & \begin{array}{c}{\left[\mathrm{CaCl}_{2}\right]} \\ (\mathrm{mM})\end{array} & \begin{array}{c}{[\mathrm{SRHA}]} \\ (\mathrm{mg} / \mathrm{L})\end{array} & \begin{array}{c}\alpha_{\text {hetero }}(\text { model } \\ \text { estimate })\end{array} & \begin{array}{c}\alpha_{\text {hetero }} \\ \left(\text { classes }^{b}\right)\end{array} \\ 5 & 1 & & & 0.9 & \text { high } \\ 8 & 1 & & <0.001 & \text { low } \\ 8 & 10 & & <0.001 & \text { low } \\ 8 & 25 & & <0.001 & \text { low } \\ 8 & 50 & & 0.3 & \text { intermediate } \\ 8 & 100 & & 0.8 & \text { high } \\ 8 & & 0.05 & & <0.001 & \text { low } \\ 8 & & 0.1 & & 0.3 & \text { intermediate } \\ 8 & & 1 & & 1.1 & \text { high } \\ 8 & 100 & & 0.1 & 0.5 & \text { high } \\ 8 & 100 & & 1.0 & 0.02 & \text { low } \\ 8 & 100 & & 10 & <0.001 & \text { low } \\ 8 & & 5 & 0.1 & 1.1 & \text { high } \\ 8 & & 5 & 1.0 & 0.3 & \text { intermediate } \\ 8 & & 5 & 10 & 0.2 & \text { intermediate }\end{array}$

${ }^{a}$ Both the explicit $\alpha_{\text {hetero }}$ values estimated with the Smolu-Model and the assigned classes (high, intermediate and low) into which the $\alpha_{\text {hetero }}$ values fall are displayed. ${ }^{b}$ High: $\alpha_{\text {hetero }} \geq 0.5$. Intermediate: $0.1 \leq \alpha_{\text {hetero }}$ $<0.5$. Low: $\alpha_{\text {hetero }}<0.1$.

the different aggregation mechanisms for homo- versus heteroaggregation, the Smolu-Model was parametrized with a rectilinear collision mode for the $\mathrm{SiO}_{2}-\mathrm{TiO}_{2}$ heteroaggregation and with an intermediate collision mode for the $\mathrm{SiO}_{2}$ homoaggregation.

At $\mathrm{pH} 8$ the $\mathrm{SiO}_{2}$ particles are stable under all studied conditions, so the increase in size measured by laser diffraction in the heteroaggregation experiments is not affected by homoaggregation of the $\mathrm{SiO}_{2}\left(\alpha_{\mathrm{homo}}^{\mathrm{SiO}_{2}}<0.001\right.$ in all cases). The $\mathrm{TiO}_{2}$ NPs, on the other hand, exhibit $\alpha_{\text {homo }}^{\mathrm{TiO}_{2}}>0.1$ under some electrolyte conditions. Concurrent homoaggregation of the $\mathrm{TiO}_{2} \mathrm{NPs}$ could in principle affect the heteroaggregation mechanism and induce errors in eq 1 by affecting $f_{\mathrm{NP}}$ and the assumption of uniform $\mathrm{TiO}_{2}$ distribution on the $\mathrm{SiO}_{2}$ surface. However, because the $\mathrm{TiO}_{2}$ concentration is much lower than the $\mathrm{SiO}_{2}$ concentration the collision frequency of the $\mathrm{TiO}_{2}$ particles is much lower than their collision frequency with the $\mathrm{SiO}_{2}$ particles, so the actual homoaggregation rate of $\mathrm{TiO}_{2}$ is very slow, even at $\alpha_{\text {homo }}^{\mathrm{TiO}_{2}}$ values exceeding 0.1 . Therefore, the method presented here can be used to determine $\alpha_{\text {hetero }}$ values even under conditions where homoaggregation of the NPs cannot be excluded.

The $\alpha_{\text {hetero }}$ values displayed in Table 1 show that the heteroaggregation behavior of $\mathrm{SiO}_{2}$ and $\mathrm{TiO}_{2} \mathrm{NPs}$ at $\mathrm{pH} 8$ follows the trends predicted by DLVO theory. At low electrolyte conditions no heteroaggregation is observed ( $\alpha_{\text {hetero }}$ $<0.001$ ), which can be explained by the repulsive charges of the particles stabilizing the system. $\alpha_{\text {hetero }}$ increases with increasing electrolyte concentration and the divalent electrolyte $\left(\mathrm{CaCl}_{2}\right)$ destabilizes the system at lower concentrations than the monovalent electrolyte $(\mathrm{NaCl})$ as predicted by the SchulzeHardy rule. $^{26,27}$

Influence of SRHA on Heteroaggregation Kinetics. To reflect more realistic environmental conditions the heteroaggregation experiments were repeated in the presence of Suwanee River Humic Acid (SRHA) at 0.1, 1.0, and $10 \mathrm{mg} / \mathrm{L}$ at pH 8 (Figure 3, Supporting Information Figure S8, Table 1). The addition of SRHA results in a more negative charge on the $\mathrm{SiO}_{2}$ surface (Figure S9 in the Supporting Information), with the lowest EPM reached with $1.0 \mathrm{mg} / \mathrm{L}$ SRHA. Increase to 10 $\mathrm{mg} / \mathrm{L}$ SRHA only leads to a negligible further decrease of the EPM, suggesting that at $1 \mathrm{mg} / \mathrm{L}$ SRHA the maximum adsorbed humid acid mass is reached. This is reflected by the heteroaggregation behavior of the $\mathrm{SiO}_{2}-\mathrm{TiO}_{2}$ system in the presence of SRHA. Both at $100 \mathrm{mM} \mathrm{NaCl}$ and at $5 \mathrm{mM} \mathrm{CaCl}_{2}$ the heteroaggregation rate is only slightly reduced in the presence of $0.1 \mathrm{mg} / \mathrm{L} \mathrm{SRHA}\left(\alpha_{\text {hetero }}=0.5\right.$ and 1.1 for $100 \mathrm{mM}$ $\mathrm{NaCl}$ and $5 \mathrm{mM} \mathrm{CaCl}_{2}$, respectively), whereas $1.0 \mathrm{mg} / \mathrm{L} \mathrm{SRHA}$ strongly stabilizes the system $\left(\alpha_{\text {hetero }}=0.02\right.$ and 0.3$)$ and an increase to $10 \mathrm{mg} / \mathrm{L}$ SRHA causes little additional stabilization $\left(\alpha_{\text {hetero }}<0.001\right.$ and $\left.\alpha_{\text {hetero }}=0.2\right)$. The experiments show that SRHA has a similarly stabilizing effect toward heteroaggregation as has been repeatedly demonstrated for homoaggregation of NPs, ${ }^{28-36}$ probably through a combination of electrostatic and steric stabilization mechanisms.

\section{LIMITATIONS AND OUTLOOK}

We use a combination of time-resolved laser diffraction measurements and a Smoluchowski-based aggregation model to determine concentration-independent attachment efficiencies for heteroaggregation, $\alpha_{\text {hetero }}$, between nanoparticles (NPs) and natural colloids (NCs). Our new method is flexible and can be applied to a wide range of different NPs and NCs and is not limited to specific solution chemistries.

The current version of the Smolu-Model is only able to model a simplified representation of the actual heteroaggregation processes as it only explicitly models the secondary heteroaggregation process (aggregation of the primary heteroaggregates). The uncertainty resulting from backcalculating $\alpha_{\text {hetero }}$ from $\alpha_{\text {global }}$ using eq 1 cannot be assessed quantitatively. Therefore, the $\alpha_{\text {hetero }}$ values displayed in Table 1 represent first estimates of the attachment efficiencies for heteroaggregation under the given conditions but cannot yet be taken as definite $\alpha_{\text {hetero }}$ values. For this reason, we prefer to group the derived $\alpha_{\text {hetero }}$ values into three major classes of "high", "intermediate", and "low" attachment (Table 1). Because of the inherent complexity of the natural environmental and the scarcity of data on ENP emissions and behavior, environmental fate models for ENP are not highly sensitive to small changes in $\alpha_{\text {hetero }}$ and therefore the distinction between three different classes for $\alpha_{\text {hetero }}$ will be sufficient in most cases.

In the future, the Smolu-Model will be further developed, using experiments characterizing the specific interactions between NCs, NPs and NOM within the aquatic medium. This will make it possible to specifically model the primary heteroaggregation step, similarly to the model presented by Therezien et al., ${ }^{37}$ and thereby refine our method and enable the derivation of more accurate $\alpha_{\text {hetero }}$ values. Additionally, the 
method presented here will be extended to be applicable to more realistic systems. Preliminary results of a heteroaggregation study with $\mathrm{TiO}_{2} \mathrm{NPs}$ and natural suspended matter sampled from the Rhône river (France) are presented in section S5 of the Supporting Information. Two strategies may be employed to derive $\alpha_{\text {hetero }}$ for such complex systems. One option would be to further develop the Smolu-Model to represent different types of NC with varying size distributions. This is in theory feasible but will require large computational efforts. Alternatively, after identifying and characterizing the different NCs in the natural samples, individual heteroaggregation experiments with the dominant NC types could be performed to derive $\alpha_{\text {hetero }}$ for the different NCs.

The new method presented here is a step toward the systematic determination of accurate $\alpha_{\text {hetero }}$ values for the heteroaggregation between NPs and NCs, which are crucially needed as input parameters into environmental fate models for ENPs. This study therefore represents an important contribution to improving ENP fate and, ultimately, risk assessment.

\section{ASSOCIATED CONTENT}

\section{(5 Supporting Information}

More details on the Smolu-Model, including a short description of the model, the derivation of eq 1 , and the model input parameters, together with additional data on aggregation kinetics and particle characterization. This material is available free of charge via the Internet at http://pubs.acs.org/.

\section{AUTHOR INFORMATION}

\section{Corresponding Author}

*E-mail: antonia.praetorius@chem.ethz.ch.

\section{Notes}

The authors declare no competing financial interest.

\section{ACKNOWLEDGMENTS}

This work was funded by the Swiss National Science Foundation (NRP 64) and the French National Research Agency (P2N MESONNET and NANOHETER under the frame of SINN, the ERA-NET for a Safe Implementation of Innovative Nanoscience and Nanotechnology). We thank Stéphanie Gairoard for the Rhône water samples and data on their characterization, Cristian Conteduca for support with the aggregation modelling, and Mark Wiesner and Mathieu Therezien for fruitful discussions.

\section{REFERENCES}

(1) Praetorius, A.; Arvidsson, R.; Molander, S.; Scheringer, M. Facing Complexity through Informed Simplifications: A Research Agenda for Aquatic Exposure Assessment of Nanoparticles. Environ. Sci.: Processes Impacts 2013, 15, 161-168.

(2) Alvarez, P. J. J.; Colvin, V.; Lead, J.; Stone, V. Research Priorities to Advance Eco-Responsible Nanotechnology. ACS Nano 2009, 3, 1616-1619.

(3) Auffan, M.; Pedeutour, M.; Rose, J.; Masion, A.; Ziarelli, F.; Borschneck, D.; Chaneac, C.; Botta, C.; Chaurand, P.; Labille, J.; Bottero, J.-Y. Structural Degradation at the Surface of a $\mathrm{TiO}_{2}$-Based Nanomaterial Used in Cosmetics. Environ. Sci. Technol. 2010, 44, 2689-2694.

(4) Labille, J.; Feng, J.; Botta, C.; Borschneck, D.; Sammut, M.; Cabie, M.; Auffan, M.; Rose, J.; Bottero, J.-Y. Aging of $\mathrm{TiO}_{2}$ Nanocomposites Used in Sunscreen. Dispersion and Fate of the Degradation Products in Aqueous Environment. Environ. Pollut. 2010, 158, 3482-3489.
(5) Lowry, G. V.; Gregory, K. B.; Apte, S. C.; Lead, J. R. Transformations of Nanomaterials in the Environment. Environ. Sci. Technol. 2012, 46, 6893-6899.

(6) Solovitch, N.; Labille, J.; Rose, J.; Chaurand, P.; Borschneck, D.; Wiesner, M. R.; Bottero, J.-Y. Concurrent Aggregation and Deposition of $\mathrm{TiO}_{2}$ Nanoparticles in a Sandy Porous Media. Environ. Sci. Technol. 2010, 44, 4897-4902.

(7) Clemente, Z.; Castro, V. L.; Feitosa, L. O.; Lima, R.; Jonsson, C. M.; Maia, A. H. N.; Fraceto, L. F. Fish Exposure to Nano-TiO ${ }_{2}$ under Different Experimental Conditions: Methodological Aspects for Nanoecotoxicology Investigations. Sci. Total Environ. 2013, 463464, 647-656.

(8) Petosa, A. R.; Jaisi, D. P.; Quevedo, I. R.; Elimelech, M.; Tufenkji, N. Aggregation and Deposition of Engineered Nanomaterials in Aquatic Environments: Role of Physicochemical Interactions. Environ. Sci. Technol. 2010, 44, 6532-6549.

(9) Gallego-Urrea, J. A.; Perez Holmberg, J.; Hassellöv, M. Influence of Different Types of Natural Organic Matter on Titania Nanoparticle Stability: Effects of Counter Ion Concentration and pH. Environ. Sci.: Nano 2014, 1, 181-189.

(10) Liu, J.; Legros, S.; von der Kammer, F.; Hofmann, T. Natural Organic Matter Concentration and Hydrochemistry Influence Aggregation Kinetics of Functionalized Engineered Nanoparticles. Environ. Sci. Technol. 2013, 47, 4113-4120.

(11) Liu, X.; Chen, G.; Keller, A. A.; Su, C. Effects of Dominant Material Properties on the Stability and Transport of $\mathrm{TiO}_{2}$ Nanoparticles and Carbon Nanotubes in Aquatic Environments: From Synthesis to Fate. Environ. Sci.: Processes Impacts 2013, 15, 169189.

(12) Praetorius, A.; Scheringer, M.; Hungerbühler, K. Development of Environmental Fate Models for Engineered Nanoparticles-A Case Study of $\mathrm{TiO}_{2}$ Nanoparticles in the Rhine River. Environ. Sci. Technol. 2012, 46, 6705-6713.

(13) Gottschalk, F.; Sonderer, T.; Scholz, R. W.; Nowack, B. Modeled Environmental Concentrations of Engineered Nanomaterials $\left(\mathrm{TiO}_{2}, \mathrm{ZnO}, \mathrm{Ag}, \mathrm{CNT}\right.$, Fullerenes) for Different Regions. Environ. Sci. Technol. 2009, 43, 9216-9222.

(14) Gottschalk, F.; Ort, C.; Scholz, R. W.; Nowack, B. Engineered Nanomaterials in Rivers-Exposure Scenarios for Switzerland at High Spatial and Temporal Resolution. Environ. Pollut. 2011, 159, 34393445.

(15) Keller, A.; McFerran, S.; Lazareva, A.; Suh, S. Global Life Cycle Releases of Engineered Nanomaterials. J. Nanopart. Res. 2013, 15, 117.

(16) Zhou, D.; Abdel-Fattah, A. I.; Keller, A. A. Clay Particles Destabilize Engineered Nanoparticles in Aqueous Environments. Environ. Sci. Technol. 2012, 46, 7520-7526.

(17) Huynh, K. A.; McCaffery, J. M.; Chen, K. L. Heteroaggregation of Multiwalled Carbon Nanotubes and Hematite Nanoparticles: Rates and Mechanisms. Environ. Sci. Technol. 2012, 46, 5912-5920.

(18) Afrooz, A. R. M. N.; Khan, I. A.; Hussain, S. M.; Saleh, N. B. Mechanistic Heteroaggregation of Gold Nanoparticles in a Wide Range of Solution Chemistry. Environ. Sci. Technol. 2013, 47, 18531860.

(19) Loosli, F.; Stoll, S. Adsorption of $\mathrm{TiO}_{2}$ Nanoparticles at the Surface of Micron-Sized Latex Particles. $\mathrm{pH}$ and Concentration Effects on Suspension Stability. J. Colloid Sci. Biotechnol. 2012, 1, 1-9.

(20) Hogg, R.; Healy, T. W.; Fuerstenau, D. W. Mutual Coagulation of Colloidal Dispersions. Trans. Faraday Soc. 1966, 62, 1638-1651.

(21) Bizi, M.; Baudet, G. Contribution of Static Light Scattering to the Textural Characterization of Large Aggregates. J. Colloid Interface Sci. 2006, 300, 200-209.

(22) Thill, A.; Moustier, S.; Aziz, J.; Wiesner, M. R.; Bottero, J. Y. Flocs Restructuring during Aggregation: Experimental Evidence and Numerical Simulation. J. Colloid Interface Sci. 2001, 243, 171-182.

(23) Lin, S.; Wiesner, M. R. Deposition of Aggregated Nanoparticles-A Theoretical and Experimental Study on the Effect of Aggregation State on the Affinity between Nanoparticles and a Collector Surface. Environ. Sci. Technol. 2012, 46, 13270-13277. 
(24) Thill, A.; Lambert, S.; Moustier, S.; Ginestet, P.; Audic, J. M.; Bottero, J. Y. Structural Interpretations of Static Light Scattering Patterns of Fractal Aggregates: II. Experimental Study. J. Colloid Interface Sci. 2000, 228, 386-392.

(25) Veerapaneni, S.; Wiesner, M. R. Hydrodynamics of Fractal Aggregates with Radially Varying Permeability. J. Colloid Interface Sci. 1996, 177, 45-57.

(26) Hardy, W. B. A Preliminary Investigation of the Conditions which Determine the Stability of Irreversible Hydrosols. J. Phys. Chem. 1899, 4, 235-253.

(27) Overbeek, J. T. G. The Rule of Schulze and Hardy. Pure Appl. Chem. 1980, 52, 1151-1161.

(28) von der Kammer, F.; Ottofuelling, S.; Hofmann, T. Assessment of the Physico-chemical Behavior of Titanium Dioxide Nanoparticles in Aquatic Environments Using Multi-Dimensional Parameter Testing. Environ. Pollut. 2010, 158, 3472-3481.

(29) Ottofuelling, S.; von der Kammer, F.; Hofmann, T. Commercial Titanium Dioxide Nanoparticles in Both Natural and Synthetic Water: Comprehensive Multidimensional Testing and Prediction of Aggregation Behavior. Environ. Sci. Technol. 2011, 45, 10045-10052.

(30) Louie, S. M.; Tilton, R. D.; Lowry, G. V. Effects of Molecular Weight Distribution and Chemical Properties of Natural Organic Matter on Gold Nanoparticle Aggregation. Environ. Sci. Technol. 2013, 47, 4245-4254.

(31) Keller, A. A.; Wang, H.; Zhou, D.; Lenihan, H. S.; Cherr, G.; Cardinale, B. J.; Miller, R.; Ji, Z. Stability and Aggregation of Metal Oxide Nanoparticles in Natural Aqueous Matrices. Environ. Sci. Technol. 2010, 44, 1962-1967.

(32) Dong, H.; Lo, I. M. C. Influence of Humic Acid on the Colloidal Stability of Surface-Modified Nano Zero-Valent Iron. Water Res. 2013, 47, 419-427.

(33) Hyung, H.; Fortner, J. D.; Hughes, J. B.; Kim, J.-H. Natural Organic Matter Stabilizes Carbon Nanotubes in the Aqueous Phase. Environ. Sci. Technol. 2007, 41, 179-184.

(34) Zhang, Y.; Chen, Y. S.; Westerhoff, P.; Crittenden, J. Impact of Natural Organic Matter and Divalent Cations on the Stability of Aqueous Nanoparticles. Water Res. 2009, 43, 4249-4257.

(35) Saleh, N. B.; Pfefferle, L. D.; Elimelech, M. Influence of Biomacromolecules and Humic Acid on the Aggregation Kinetics of Single-Walled Carbon Nanotubes. Environ. Sci. Technol. 2010, 44, 2412-2418.

(36) Quik, J. T. K.; Lynch, I.; Hoecke, K. V.; Miermans, C. J. H.; Schamphelaere, K. A. C. D.; Janssen, C. R.; Dawson, K. A.; Stuart, M. A. C.; Meent, D. V. D. Effect of Natural Organic Matter on Cerium Dioxide Nanoparticles Settling in Model Fresh Water. Chemosphere 2010, 81, 711-715.

(37) Therezien, M.; Thill, A.; Wiesner, M. R. Importance of heterogeneous aggregation for NP fate in natural and engineered systems. Sci. Total Environ. 2014, 485-486, 309-318. 